\title{
SESSION VIII
}

\section{COMPSYCH: A DEMONSTRATION AND PROGRESS REPORT}

Margaret Anderson and Peter Hornby, Presiders

State University of New York, College at Plattsburgh

\section{COMPsych: A description and progress report}

\author{
MARGARET ANDERSON and PETER HORNBY \\ State University of New York College at Plattsburgh, Plattsburgh, New York
}

\begin{abstract}
COMPsych, a computerized software information system for psychologists, is described. Also included is information on how to access the system and a description of the information available from the system. A summary and analysis of the activity on the system during the first 5 months of operation and a consideration of possible future directions are also provided.
\end{abstract}

The original design of COMPsych, a computerized system dedicated to the collection and dissemination of information about psychology software and its users, was presented at the 1987 meeting of the Society for Computers in Psychology (Anderson, Hornby, \& Bozak, 1988). At that time, we sought and obtained several valuable ideas from those in attendance concerning the design of the system, which subsequently was developed and put on line the first of June, 1988.

COMPsych presently provides four major services: (1) a catalog of descriptive information about available software, (2) a directory of software users, (3) a message system for sharing information among users, and (4) an announcement service for conferences, workshops, important publications, and other information.

In this paper, we provide specific information on how to access COMPsych and describe the types of information that are currently available from the system. We also present a summary and analysis of the activity on the system during the first 5 months of operation and describe our current goals and possible directions for the future.

\section{Accessing COMPsych}

The COMPsych bulletin board and the primary databases are maintained by the authors at the State University of New York College at Plattsburgh and can be directly accessed using a PC and modem. The phone number for modem access is (518) 564-3372, operating at

Requests for reprints may be sent to Margaret Anderson, Department of Psychology, State University of New York College at Plattsburgh, Plattsburgh, NY 12901.
1200 baud using 8 data bits, no parity, and 1 stop bit. COMPsych runs under RBBS-PC, a general purpose public domain bulletin board software system that has been specifically configured for the COMPsych system. Use of a modem is the preferred method of access because it is fully interactive, supports downloading of all files, allows capturing of complete transactions, and permits use of the message system.

Information also can be obtained and submitted to COMPsych via electronic mail. Users on the BITNET system may request information by sending a plain language request to <COMPSYCH@SNYPLABA $>$. In addition, a secondary COMPsych database is maintained by David Bozak at the State University of New York College at Oswego. Individuals who have access to the Internet can send mail or obtain anonymous ftp access to <compsych@cleo.oswego.edu>. The Internet address is 129.3.2.2. Files are located in pub and there is a help file describing the contents. Unix users who only have access to UUCP should use \{rutgers, rochester\}!sunybcs!oswego! cleo!compsych.

Users who cannot obtain access by modem or electronic mail should write to COMPsych, Department of Psychology, State University College, Plattsburgh, NY 12901. Regardless of method of access, all users will be provided with basic instructions regarding the use of COMPsych and may become registered COMPsych users.

\section{What Is Available from COMPsych?}

Individuals accessing COMPsych by modem may use the interactive bulletin board system to exchange information, to communicate with the system operators and other users, and to view, or download, any information 
contained in the COMPsych databases. After logging onto COMPsych, the user is presented with a brief description of the system and is asked to enter his/her name, address, and a password to be used for future access. Following this, the user can obtain direct access to the COMPsych databases from a menu selection. All COMPsych files are maintained as bulletins in ASCII format, and the initial Bulletin Menu lists the primary bulletins that are available for viewing. These include, but are not limited to, the following: (1) User Information: a comprehensive description of the COMPsych system, methods of access, and user instructions; (2) Conferences: a listing of conferences of potential interest to psychology software users with dates, locations, and contact persons; (3) New Software Listings: a listing of all software descriptions entered during the previous month; (4) Directory of Software Categories: a list of the specific categories that are used to classify psychology software (e.g., General, Developmental, Cognition, Statistics Tutorials, Clinical Diagnosis, etc.); (5) Alphabetical List of Cataloged Software: a listing of all software (by title only) that is presently cataloged, with the appropriate category identified; (6) Directory of User Specializations: a list of the interest areas (e.g., Development, Research Methods, etc.) under which users are registered; (7) Alphabetical Directory of Users: a list (by name only) of all registered COMPsych users indicating their geographical location and the specialization areas under which they are registered; (8) Catalog of Books: a list of books and journals on the general topic of using computers in psychology instruction, research, or practice.

After identifying the appropriate subcategory listings in Bulletins 4, 5, 6, or 7 above, users can directly access the specific bulletin of interest and then view the descriptions of all software cataloged in that area. The most recently cataloged software is listed first. For each item cataloged, the description contains the title, author(s), publisher's name and address, a brief description of the software, its intended function (instruction, research, or practice), required hardware, availability of the source code, site license and documentation, the selling price, and a listing of published reviews and/or user comments. The user specialization bulletins contain each user's name, address, telephone number, E-mail address, and a code indicating the type of hardware used, primary activity (instruction, research, or practice), whether the user is a software developer, and any areas under which the user has his/her own software listed with COMPsych.

At any time after logging on, users have the option to move to the Main Bulletin Board Menu, which provides commands to leave messages for other users (which may be password-protected), to read messages addressed to them, or to leave comments for the system operator. Users may also download any of the bulletins included in the databases or complete one or more questionnaires. All users are encouraged to complete the REGISTER questionnaire to provide the information needed for the User Directory. Two other standard questionnaires are avail- able: one for submitting software descriptions to be included in the Catalog (SOFTFORM), and another for providing comments on software (REVIEW). Help files, which may be accessed at any time, are available for all bulletin board functions.

Users who access COMPsych through BITNET will be sent copies of Bulletin 1, User Information, and a copy of the registration form, REGISTER, so that they can be included in the User Directory. BITNET users also may submit requests for copies of specific COMPsych bulletins (up to three at a time) as described above. Users may request the SOFTFORM and REVIEW questionnaires for submission of appropriate information. In addition, all registered BITNET users will automatically receive the COMPsych Monthly Newsletter. The newsletter contains announcements and requests for information submitted by users, open messages on the bulletin board, a list of all new software titles added to the software catalog during the previous month, descriptions of any modifications to the COMPsych system, and other items of general interest.

Users contacting COMPsych by hard copy will also receive a copy of Bulletin 1, User Information, a copy of REGISTER, and specific instructions for obtaining other COMPsych bulletins and such questionnaires as SOFTFORM and REVIEW.

The availability of useful and accurate information from COMPsych is primarily dependent on user input. Although the system operators will include reliable information obtained from other sources (such as vendor catalogs, published announcements, and direct communication), active support by interested users is necessary to keep the system current and to provide the most useful information for other users. Although the basic design of the system has come from the developers, COMPsych is intended to be flexible and responsive to user needs and requests.

\section{Activity on COMPsych}

The material in this section represents a summary of the activity recorded on COMPsych from June, 1988 to November, 1988. Any interpretations of these data must be considered extremely tentative due to the fact that they represent only the initial months of the system's operation. However, the authors believe that these data suggest some interesting trends in hardware and software use in the various areas of psychology, and indicate the potential wealth of information that can be obtained from the COMPsych system and its users.

An analysis of activity by month (see Table 1) indicates that use of the system has remained relatively constant. The heaviest use has been by modem access. The number of actual registrations, however, has been higher for BITNET users. This difference can be accounted for, in part, by the higher number of repeat calls via modem.

At the time of writing, COMPsych listed a total of 311 pieces of software. Table 2 provides a breakdown of the number of pieces of software listed in each of the 18 con- 
Table 1

Analysis of Activity by Month

\begin{tabular}{lrrrrrr}
\hline & \multicolumn{5}{c}{ Month (6/1/88-10/30/88) } \\
\cline { 2 - 7 } \multicolumn{1}{c}{ Type of Activity } & Jun. & Jul. & Aug. & Sep. & Oct. & Total \\
\hline Modem Access Calls & 25 & 38 & 47 & 31 & 36 & 177 \\
BITNET Access Calls & 7 & 35 & 54 & 21 & 13 & 130 \\
Hard Copy Contacts & 6 & 5 & 5 & 20 & 8 & 44 \\
Modem Registrations & 4 & 5 & 9 & 4 & 9 & 31 \\
BITNET Registrations & 8 & 13 & 20 & 8 & 7 & 56 \\
Hard Copy Registrations & - & 2 & 3 & 1 & 2 & 8 \\
Software Directory Requests & 3 & 15 & 6 & 12 & 4 & 40 \\
User Directory Requests & - & - & 5 & 4 & 3 & 12 \\
Hard Copy Requests & - & - & 3 & - & 4 & 7 \\
\hline
\end{tabular}

tent areas. For each piece listed, there is an indication of the principle function (research, instruction, or practice), the hardware required to run it (IBM, Apple, MacIntosh, or other), and the number of times the bulletin containing the software listing for each area has been requested through BITNET or by hard copy. (No data are available for this column for modem or Internet users.) Statistics of this nature, when gathered over a longer period of time, should provide valuable information to both individuals and commercial concerns when deciding on areas for further software development. At this time, it is interesting to note the considerable variation in function, hardware required, and availability of freeware in the different areas. It is also interesting to note the discrepancy between the areas that have the highest number of pieces of software listed (e.g., Testing [Personality]) and the bulletins that have been requested most frequently (e.g., Cognition and Sensation/Perception). This may be due to such factors as the availability of other software information sources in the clinical areas and the specific interests of those individuals who use electronic mail systems.
Table 3 provides a breakdown of the interest areas of the 95 COMPsych users who registered during the first 5 months. (Users may indicate up to three areas of interest.) Perhaps not surprisingly, the areas best represented include Cognition, Research Methods, Experimental, and Statistics. However, the areas of Clinical and Testing also are well represented. Table 3 also contains information provided by these individuals concerning the types of hardware they use, their primary uses of computers (research, instruction, or practice), and if they are software developers and electronic mail users. One trend that can be seen in these preliminary data is the difference in the types of hardware being used by individuals in different content areas. Also, such areas as Cognition, Research Methods, Statistics, and Sensation/Perception have a relatively high percentage of users who are software developers and who are also users of electronic mail. Information of this nature, when gathered over a longer period of time, should prove valuable to software developers and to individuals considering the purchase of hardware for specific content area use.

COMPsych provides a direct service to psychologists by providing information about software and software users. The collection of data of the type shown in Tables 2 and 3 is an additional benefit of this system that should prove quite useful to those interested in psychology software.

\section{Future Directions for COMPsych}

The primary goal of COMPsych is to serve as a central mechanism for the collection and dissemination of information about software and its users in all areas of psychology. Another main goal is to provide those users with a convenient means of communicating with each other. To further improve communication among software users,

Table 2

Analysis of Software Characteristics by Category

\begin{tabular}{|c|c|c|c|c|c|c|c|c|c|c|}
\hline \multirow[b]{2}{*}{ Software Category } & \multirow{2}{*}{$\begin{array}{l}\text { No. of } \\
\text { Items }\end{array}$} & \multicolumn{3}{|c|}{ Function } & \multicolumn{4}{|c|}{ Hardware Required } & \multirow{2}{*}{$\begin{array}{c}\text { Freeware } \\
(<\$ 5)\end{array}$} & \multirow{2}{*}{$\begin{array}{c}\text { No. of } \\
\text { Requests }\end{array}$} \\
\hline & & Res. & Inst. & Pract. & IBM & Apple & Mac & Other & & \\
\hline General & 14 & - & 14 & - & 9 & 10 & 2 & 1 & - & 4 \\
\hline Developmental & 5 & - & - & 5 & 5 & 4 & - & - & - & 1 \\
\hline Physiological & 3 & 1 & 2 & 2 & - & 1 & - & 3 & - & 3 \\
\hline Sensation/Perception & 11 & - & 11 & - & 5 & 4 & - & 2 & 2 & 7 \\
\hline Cognition & 7 & - & 7 & - & 2 & 6 & - & 1 & 1 & 7 \\
\hline Learning & 12 & 2 & 10 & 2 & 4 & 6 & - & 3 & 1 & 6 \\
\hline Industrial/Organizational & 6 & - & - & 6 & 6 & 1 & - & - & - & 1 \\
\hline Statistics (Tutorial) & 9 & - & 9 & - & 2 & 6 & 1 & - & 1 & 1 \\
\hline Statistics (Computational) & 28 & 27 & 11 & - & 23 & 8 & 3 & 2 & 5 & 4 \\
\hline Research Methods & 28 & 16 & 25 & - & 16 & 19 & 6 & 1 & 3 & 6 \\
\hline Social & 5 & - & 5 & - & 3 & 5 & - & - & - & 1 \\
\hline Testing (Personality) & 50 & - & - & 50 & 47 & 28 & 1 & 1 & - & - \\
\hline Testing (Intelligence) & 17 & 1 & - & 17 & 16 & 14 & 2 & - & - & - \\
\hline Testing (Vocational) & 10 & - & - & 10 & 10 & 7 & - & - & - & 1 \\
\hline Testing (Other) & 12 & 2 & - & 10 & 11 & 8 & - & 1 & - & - \\
\hline Clinical (Diagnostic) & 23 & 1 & 3 & 21 & 21 & 8 & - & - & - & 1 \\
\hline Clinical (Other) & 31 & - & 4 & 26 & 28 & 16 & 0 & 3 & - & - \\
\hline Counseling & 40 & 2 & 3 & 36 & 25 & 25 & 1 & 1 & - & 1 \\
\hline TOTAL & 311 & 53 & 104 & 185 & 233 & 176 & 16 & 19 & 13 & 44 \\
\hline
\end{tabular}

Note - Res. $=$ research; Inst. $=$ instruction; Pract. $=$ practice . 
Table 3

Analysis of Registered Users

\begin{tabular}{|c|c|c|c|c|c|c|c|c|c|}
\hline \multirow[b]{2}{*}{ Interest Areas } & \multirow{2}{*}{$\begin{array}{l}\text { No. of } \\
\text { Users }\end{array}$} & \multicolumn{3}{|c|}{ Hardware Used } & \multicolumn{3}{|c|}{ Function } & \multirow{2}{*}{$\begin{array}{l}\text { Software } \\
\text { Developer }\end{array}$} & \multirow{2}{*}{$\begin{array}{c}\text { E-Mail } \\
\text { Users }\end{array}$} \\
\hline & & IBM & Apple & Other & Res. & Inst. & Pract. & & \\
\hline General & 12 & 9 & 5 & 3 & 5 & 8 & 2 & 6 & 10 \\
\hline Developmental & 4 & 2 & 2 & 2 & 2 & 2 & 1 & 3 & 3 \\
\hline Physiological & 9 & 6 & 3 & 2 & 5 & 1 & 1 & 2 & 4 \\
\hline Sensation/Perception & 16 & 11 & 8 & 6 & 12 & 6 & - & 8 & 13 \\
\hline Cognition & 25 & 17 & 15 & 8 & 19 & 11 & 1 & 20 & 23 \\
\hline Learning & 11 & 6 & 5 & 5 & 6 & 6 & 1 & 5 & 8 \\
\hline Industrial/Organizational & 5 & 5 & - & 1 & 3 & - & 1 & 1 & 3 \\
\hline Animal Behavior & 4 & 3 & 1 & 2 & 3 & 1 & - & 2 & 3 \\
\hline History \& Systems & 2 & - & 2 & 1 & 1 & 1 & - & 2 & 1 \\
\hline Statistics & 20 & 13 & 9 & 7 & 15 & 5 & 3 & 5 & 2 \\
\hline Social & 7 & 4 & 3 & 2 & 4 & 4 & - & 3 & 7 \\
\hline Personality & 9 & 5 & 3 & 1 & 4 & 2 & 1 & 5 & 5 \\
\hline Clinical & 25 & 14 & 7 & 7 & 10 & 1 & 12 & 3 & 8 \\
\hline Counseling & 9 & 7 & 6 & - & 5 & 2 & 2 & 3 & 5 \\
\hline Testing & 17 & 12 & 4 & 3 & 8 & - & 7 & 7 & 4 \\
\hline Educational & 8 & 4 & 5 & 1 & 4 & 5 & - & 3 & 6 \\
\hline School & 4 & 4 & 1 & 1 & 1 & 1 & 3 & 1 & 1 \\
\hline Experimental & 20 & 12 & 11 & 4 & 13 & 10 & 2 & 13 & 15 \\
\hline Research Methods & 27 & 19 & 10 & 6 & 17 & 9 & 3 & 14 & 20 \\
\hline Sport & - & - & - & - & - & - & - & - & - \\
\hline Other & 15 & 7 & 6 & 6 & 10 & - & 4 & 6 & 6 \\
\hline TOTAL & 249 & 160 & 106 & 68 & 137 & 75 & 44 & 120 & 159 \\
\hline
\end{tabular}

Note - Res. $=$ research; Inst. $=$ instruction; Pract. $=$ practice.

COMPsych could provide support for special interest group conferences on the bulletin board. Electronic mail distribution lists of individuals interested in specified topics also could be maintained. The newsletter could be expanded to include additional information and to further support communication among users. It is anticipated that the use of the existing message system will continue to grow. Additional bulletins covering special interest topics could be included (such as a bulletin devoted to listing other relevant bulletin boards and other sources of information about psychology software). There are two additional areas in which this system could expand to provide valuable and currently unavailable services. The first is in the continued collection and analysis of data related to hardware and software uses and needs. The second is in obtaining more user comments and reviews of the listed software.

The main priorities of the system operators include continuing to obtain more information about additional software, actively encouraging individuals to register their freeware, and adapting the system to the needs and interests of users. It is expected that the system will continue to grow, that many more people will become active users, and that additional services will be made available.

\section{REFERENCE}

Anderson, M. D., Hornby, P. A., \& BozaK, D. (1988). COMPsych: A computerized software information system. Behavior Research Methods, Instruments, \& Computers, 20, 243-245. 